\title{
Potencialidades do quadro da vulnerabilidade e direitos humanos para os estudos e as práticas de prevenção às arboviroses
}

The potential of the vulnerability and human rights framework for studies and practices in the prevention of arbovirus infections

\author{
Potencialidades del cuadro de vulnerabilidad y \\ Derechos Humanos para estudios y prácticas de \\ prevención frente a arbovirosis
}

\author{
Neide Emy Kurokawa e Silva 1 \\ Miriam Ventura ${ }^{1}$ \\ César Augusto Paro 1
}

Das conferências de Alma-Ata (1978) à de Astana (2018), depreendem-se claras mudanças nos princípios norteadores da atenção primária à saúde (APS), especialmente, no deslocamento do sentido de direito: de "direito universal à saúde" para "cobertura universal de saúde", transmutando a ideia de cidadania para uma perspectiva liberal de consumo de serviços. Tal situação emerge nos avanços da globalização econômica, com a crescente participação do setor privado na constituição e no financiamento dos sistemas de saúde, que potencializa o risco de uma política privatizante e excludente de saúde, especialmente no contexto latino-americano ${ }^{1}$.

No Brasil, o reconhecimento de tal deslocamento como séria ameaça às bases constitucionais do Sistema Único de Saúde (SUS) nos impõe tanto a recusa das forças ideológicas e políticas que sustentam essa ameaça quanto o empreendimento crítico 2 de rever e reconstruir os próprios quadros de referência que vêm orientando as práticas de saúde. Afinal, a gravidade de um perigo é inversamente proporcional ao nosso conhecimento sobre o que estaria sob risco e à nossa capacidade de fazer face a ele.

Considerando a ameaça à democracia participativa, inerente à perspectiva contemporânea de direitos humanos, o presente texto visa problematizar iniciativas hegemônicas de prevenção às arboviroses, resgatando reflexões e práticas propiciadas pelo quadro da vulnerabilidade e direitos humanos.

\section{Arboviroses e as estratégias de enfrentamento: velhos "problemas", velhas "soluções"...}

No campo da prevenção de doenças e da promoção da saúde, atividades privilegiadas da APS, é histórica a reprodução de velhas estratégias que, no caso das arboviroses, privilegiam campanhas de alerta contra o mosquito e convocam a população a vigiar/cuidar dos focos domésticos, reduzindo o entendimento sobre direitos e participação, subsumindo indivíduos e população a meros objetos das intervenções.

Críticas a essas práticas vêm ocorrendo desde a década de 1980, quando o mosquito Aedes aegypti, que havia até então sido erradicado no contexto das medidas de controle da febre amarela em 1955, é reintroduzido no território nacional. Assumindo a intrínseca relação da saúde e da educação com a cidadania, pesquisadores do Centro de Estudos e Pesquisas da Leopoldina (Cepel) da Escola Nacio-
${ }^{1}$ Instituto de Estudos em Saúde Coletiva, Universidade Federal do Rio de Janeiro, Rio de Janeiro, Brasil.

\section{Correspondência} N. E. K. Silva Instituto de Estudos em Saúde Coletiva, Universidade Federal do Rio de Janeiro. Av. Horácio Macedo s $/ n$, Rio de Janeiro, $R J$ 21941-598, Brasil. neks@iesc.ufrj.br 
nal de Saúde Pública Sergio Arouca, Fundação Oswaldo Cruz (ENSP/Fiocruz) já alertavam sobre a importância de ações de mobilização social que ampliassem as estratégias de mitigação dos fatores que favorecem a proliferação dos mosquitos, como é o caso do saneamento básico ${ }^{3,4}$.

A partir de suas experiências com grupos populares em subúrbios cariocas, problematizam tanto a "ditadura da urgência”, instaurada nos momentos epidêmicos em que o poder público renega qualquer discussão sobre o sistema de abastecimento de água, quanto a "crise de interpretação" dos mediadores (profissionais, técnicos, políticos) para compreender a fala dos membros da comunidade, decorrente de uma postura que não considera que os moradores da periferia sejam capazes de produzir conhecimento e de organizar e sistematizar pensamentos sobre a sociedade, que possam, inclusive, auxiliar a própria avaliação dos mediadores sobre a mesma sociedade 3. Para fazer face a tais problemáticas, propõem repensar a participação popular no controle de endemias a partir de um processo de construção compartilhada do conhecimento que leve em conta os diversos saberes (os técnico-científicos e as experiências populares) e emerja da estruturação e do fortalecimento de redes sociais de apoio 4 .

Há também autores que advogam por novos modelos tecnológicos de organização do processo de trabalho e da atenção à saúde que se estruturem por meio da participação social, como a proposta da vigilância da saúde de base territorial 5 .

Ao retornar à cena nacional, assumindo centralidade nas ações de saúde pública, o enfrentamento das arboviroses continua sendo hegemonicamente pautado no modelo médico assistencial e sanitarista campanhista, com ações governamentais centralizadoras, modelo comunicacional de caráter vertical, pouca articulação aos determinantes sociais de saúde e ausência de territorialização e mobilização social 5 .

\section{O quadro da vulnerabilidade e direitos humanos e a crítica às práticas hegemônicas}

A distribuição de folhetos explicativos e campanhas baseadas em mutirões comunitários, visando eliminar focos do mosquito, são antigas e difundidas tecnologias de educação em saúde, fundadas em pressupostos pedagógicos baseados na transmissão de informações e mudança de comportamento dos indivíduos, culpabilizando a população pelos criadouros de larvas do Ae. aegypti.

Alguns autores 3,6,7,8 têm chamado a atenção para o fato de que, embora a informação e a mudança de comportamento possam ser consideradas nas ações de prevenção, a experiência prática tem mostrado que, isoladamente, elas são insuficientes e/ou ineficazes, bem como estratégias de amedrontamento aumentam a discriminação e o preconceito 7 .

No contexto da epidemia de aids no mundo e no Brasil, essas críticas culminaram na proposição do quadro da vulnerabilidade e direitos humanos 9,10, que permitiu que muitas das ações de prevenção ao HIV transitassem da centralidade na informação e da modelagem de comportamentos para contextos que exploram o próprio processo de discriminação e estigmatização, bem como a garantia de direitos e responsabilização dos governos, com vistas ao fomento à participação e cidadania 8 .

O conceito de vulnerabilidade abriga múltiplos sentidos, desde aqueles desenvolvidos pela bioética, evidenciando fragilidades inerentes a todo ser humano, até aqueles afiliados aos direitos humanos, denunciando as desigualdades que exprimem injustiças e opressões. Na saúde pública, tal noção, explorada inicialmente por ocasião da eclosão da epidemia de aids ${ }^{9}$, vem se aproximando dos referenciais e dos debates sobre os direitos humanos.

Passadas quase duas décadas das primeiras publicações nacionais que propõem análises a partir do quadro da vulnerabilidade e direitos humanos, é possível sintetizar alguns dos seus traços 11, que podem servir de referência para análises de vulnerabilidades às arboviroses.

Referido quadro pressupõe a articulação ativa entre teoria e prática, vislumbrando-se a retroalimentação contínua de elementos que tanto fomentam a (re)construção contínua de conhecimentos quanto de estratégias para as diferentes intervenções, considerando as experiências concretas dos indivíduos em interação.

Além disso, permite a identificação dos sentidos práticos das experiências, ou seja, dos valores, temores, percepções em jogo, diante de quaisquer eventos que ameaçam a saúde, tendo em vista que esses modelarão distintos modos de responder a eles. 
Cabe pensar, por exemplo, qual o "lugar" das arboviroses no contexto dos problemas de saúde daquele território, ressaltando-se que o pragmatismo pressuposto pelo conceito não se reduz a uma possível instrumentalidade do seu uso, mas diz respeito à fecundidade das questões que enseja: "o que está em questão, por que está, de que modo nos interpela, que alternativas nos abre, que valores e sentimentos nos despertam, que capacidades nos cobram?" 11 (p. 8).

Busca-se, aqui, portanto, superar a lógica da fatoração dos problemas ancorada na explicação, em favor de uma abordagem compreensiva que articula as diferentes dimensões que configuram tais problemas. Para tanto, a análise a partir do quadro da vulnerabilidade e direitos humanos articula as dimensões sociais mais amplas, as dimensões referentes às condições e capacidades individuais e às dimensões afetas a políticas, programas e práticas institucionalizadas dos serviços de saúde, ainda que o exame possa ser feito a partir de uma delas.

Assim, a incorporação dos direitos humanos se dá em uma perspectiva multidimensional e dinâmica, que transcende seu caráter jurídico-normativo, articulando-o a dimensões éticas, políticas, econômicas, sociais, históricas, culturais e pedagógicas 11, destacando-se suas potencialidades emancipatórias e a importância do investimento na sua dimensão pedagógica. A luta por direitos não ocorre de forma "natural", requerendo, portanto, uma formação para a participação e o exercício da cidadania, uma educação para os direitos humanos.

Diante das características ambientais das arboviroses, parece pertinente que o (re)conhecimento de vulnerabilidades tenha como ponto de partida os espaços locais em que ocorrem, tomando-os não como meros lugares que abrigam mosquitos, mas atentando para as condições desses espaços, como seus moradores apreendem e lidam com elas, quais as relações entre os espaços locais e outros espaços etc.

\section{A análise multidimensional na reconstrução das respostas às arboviroses}

Uma tentativa inicial de assimilar aspectos do quadro de vulnerabilidade e direitos humanos na promoção da saúde e prevenção dos agravos concernentes a cada uma das dimensões propostas poderia ser assim esboçada:

(i) Dimensão individual: prioridades e projetos de vida; sentidos e significados sobre as arboviroses e o território; condições e capacidade de receber, buscar e discernir criticamente informações, bem como suas fontes; condições e capacidade para o exercício da cidadania.

(ii) Dimensão programática: tipo e qualidade das informações veiculadas pelos órgãos sanitários; disponibilidade, qualidade e impacto das ações de prevenção e de promoção da saúde e demais demandas em torno dos agravos relacionados às arboviroses; consonância das políticas e práticas com os princípios do SUS; acesso a serviços públicos, em geral, e de saneamento, em especial; disponibilidade de canais de responsabilização e exigibilidade de direitos (ouvidorias, defensorias públicas etc.).

(iii) Dimensão social: interesses econômicos e políticos e suas relações com o meio ambiente e os territórios locais; contextos de restrições e violações de direitos que afetam à população local (violências, discriminação etc.); contextos favoráveis ou não a iniciativas coletivas/de participação;

contextos de produção ou de mitigação de desigualdades sociais.

Ainda que apreendida em cada uma de suas três dimensões, fica clara a interdependência entre elas, qualquer que seja o ponto de partida. O contexto de desigualdade social desfavorável a alguns segmentos populacionais, por exemplo, por si só, não impediria a existência de serviços sanitários, tampouco dependeria apenas da iniciativa dos moradores em reivindicá-los. Para que o território disponha de tais serviços, tanto é necessária a vontade política dos governantes quanto é fundamental a capacidade de organização e mobilização da população.

Inspirando-se nas lições de Paulo Freire 12 e ressaltando a sua referência crítica 2, o quadro da vulnerabilidade e direitos humanos se coaduna com a ideia da denúncia e anúncio. A denúncia se expressa na identificação de vulnerabilidades, emergindo das experiências concretas e da implicação das pessoas com os problemas de saúde, e o anúncio, enquanto possibilidade de transformação da realidade, somente se faz possível quando as reivindicações transcendem a tônica nos direitos dos sujeitos, em favor dos sujeitos de direitos 13 . 
A partir dessa perspectiva, os estudos e as práticas preventivas às arboviroses deveriam superar a lógica de "guerra ao mosquito", que se limita às campanhas massivas de eliminação de focos domésticos, para contemplar a complexidade e singularidade dos distintos contextos territoriais e as possibilidades concretas, mas ainda não experimentadas, que minimizem as vulnerabilidades ao agravo. Para isso, se faz necessário engendrar processos que promovam a participação ativa dos indivíduos que vivem naquela comunidade, permitindo, por meio do diálogo autêntico e de um agir ético-político-pedagógico guiado pela reflexão-ação-reflexão, traçar uma análise crítica que coteja o dito "problema” com os contextos que o circundam, bem como construir inéditos viáveis - projetos coletivos que traçam as possibilidades de atos criadores concretos para a transformação da realidade 14 .

Ao transcender a dimensão individual e pontual da questão, a abordagem proposta pelo quadro da vulnerabilidade e direitos humanos permite incorporar e articular, de modo mais dinâmico e integrado, outras esferas que concorrem para conformar as arboviroses como um problema sanitário, para além de um mosquito, dos recipientes no fundo dos quintais das casas e do comportamento dos indivíduos.

A contraposição aos discursos que ameaçam preceitos de direitos humanos e constitucionais e princípios éticos e políticos consagrados na APS merece nossa humildade em empreender a crítica de nossas práticas e a inovação na sua reconstrução.

\section{Colaboradores}

N. E. K. Silva elaborou o artigo, colaborou com a sua concepção, desenho e análise das informações e redação do artigo. M. Ventura colaborou na redação e revisão final da versão a ser publicada. C. A. Paro colaborou na concepção, análise e redação do artigo.

\section{Informações adicionais}

ORCID: Neide Emy Kurokawa e Silva (0000-00021314-8851); Miriam Ventura (0000-0001-85208844); César Augusto Paro (0000-0002-8447-9586).

\section{Referências}

1. Carvalho RRP, Fortes PAC, Garrafa V. Reflexiones sobre la participación pública y privada en la asistencia a la salud. Salud Pública Méx 2014; 56:221-5.

2. Nobre MS. Curso livre de teoria crítica. Campinas: Papirus; 2008.

3. Valla VV. Sobre participação popular: uma questão de perspectiva. Cad Saúde Pública 1998; 14 Suppl 2:S7-18.

4. Oliveira RM. A dengue no Rio de Janeiro: repensando a participação popular em saúde. Cad Saúde Pública 1998; 14 Suppl 2:S69-78.

5. Fernandes VR, Monken M, Gondin GMM, Luz ZMP, Lopes ABAS, Castro MC, et al. Denaturalizing "long-lasting endemic diseases": social mobilization in the context of arboviral diseases in Brazil. In: Salazar LM, Villar RCL, editors. Globalization and health inequities in Latin America. Cham: Springer; 2018. p. 91106.

6. Souza KR, Santos MLR, Guimarães ICS, Ribeiro GS, Silva LK. Saberes e práticas sobre controle do Aedes aegypti por diferentes sujeitos sociais na cidade de Salvador, Bahia, Brasil. Cad Saúde Pública 2018; 34:e00078017.

7. Ayres JRCM. Práticas educativas e prevenção de HIV/aids: lições aprendidas e desafios atuais. Interface (Botucatu) 2002; 6:11-24.

8. Paiva V. Sem mágicas soluções: a prevenção e o cuidado em HIV/aids e o processo de emancipação psicossocial. Interface (Botucatu) 2002; 6:25-38. 
9. Mann J, Tarantola DJN, Netter TW. Aids in the world. Cambridge: Harvard University Press; 1992.

10. Ayres JR, Paiva V, França Jr. I. Conceitos e práticas de prevenção: da história natural da doença ao quadro da vulnerabilidade e direitos humanos. In: Paiva V, Ayres JR, Buchalla CM, organizadores. Vulnerabilidade e direitos humanos: prevenção e promoção da saúde. Livro I: da doença à cidadania. Curitiba: Juruá; 2012. p. 71-94.

11. Ayres JRCM. Vulnerabilidade, direitos humanos e cuidado: aportes conceituais. In: Barros S, Campos PFS, Fernandes JJS, organizadores. Atenção à saúde de populações vulneráveis. Barueri: Edições Manole; 2014. p. 1-25.
12. Freire P. Pedagogia da indignação: cartas pedagógicas e outros escritos. 3a Ed. São Paulo: Paz e Terra; 2016.

13. Rifiotis T. Direitos humanos: sujeito de direitos e direitos do sujeito. In: Silveira RMG, Dias AA, Ferreira LFG, Feitosa LAPAM, Zenaide MNT, organizadores. Educação em direitos humanos: fundamentos teórico-metodológicos. João Pessoa: Editora Universitária; 2007. p. 231-44.

14. Paro CA, Ventura M, Silva NEK. Paulo Freire e o inédito viável: esperança, utopia e transformação na saúde. Trab Educ Saúde 2020; 18:e0022757. 